\title{
COVID-19: Not a Simple Public Health Emergency
}

\author{
Samuel J. Stratton, MD, MPH
}

doi:10.1017/S1049023X2000031X

Predictably, the December 2019 outbreak of a previously unknown variant of Coronavirus is the topic for this editorial. The outbreak is receiving world-wide attention and is a distraction of the news media from other world events. This editorial contains a good deal of observation and anecdotal interpretation and readers are encouraged to reply or express different opinions by submitting further editorials or sending letters to the Editor.

As is known, the outbreak is reported to first be detected in Wuhan, China and original exposures are associated with a large seafood and live animal food market. While not proven at the time this editorial is being written, it is presumed that the first human cases of COVID-19 were by animal to human transmission. Soon after "jumping" from animal to human transmission, the virus is confirmed to have been transmitted human to human. Following the original cases in Wuhan, the virus is being detected within all of China and in other areas of the world and is attributed to travel by humans. COVID-19 is presenting as a classic novel (previously unknown) infectious outbreak from which interesting observations can be made.

Recorded human history is rich in descriptions of infectious disease outbreaks and occasional pandemics. During the European middle ages, episodes of Yersinia pestis (plague) were recorded with the infectious agent transmitted by shipping from the far Eastern world to Europe by flea infested rats that had managed to board vessels. Many historians believe there is evidence to show that the H1N1 Influenza pandemic of 1918 which originated in the United States was subsequently spread to other areas of the world by World War I military troop transport to Europe and western Asia. The unintentional spread of the virus across active battle lines in Europe likely had an important impact on the outcome of the War. In more modern times, the HIV virus is thought to have initially spread from Africa by human travelers to other locations throughout the world.

As with centuries of experience with infectious disease outbreaks, COVID-19 cannot be contained due to world-wide travel by humans before the initial outbreak is detected or admitted to be occurring. Logical for containment of infectious outbreaks are advanced public health measures of monitoring and limiting close human contact for those who have been exposed to the contagion.

Most readers of Prehospital and Disaster Medicine are familiar with the health and medical aspects of disease outbreaks as discussed in the paragraphs above. Important also are global political, economic, and social impacts of disease outbreaks, such as COVID-19. Politically, such outbreaks are extremely threatening for governments of the local region and country of origin for the new disease. Emergency public health emergencies are difficult for governmental organizations to recognize and manage. Organized and effective governments generally prepare, plan, and anticipate natural disasters that are characterized by being of sudden impact, such as floods, storms, and earthquake-tsunamis. Infectious disease outbreaks are difficult for government agencies to recognize due to gradual onset and lack of damage to infrastructure (buildings and roads). Importantly, disease outbreaks require that governments support health agencies to affect and adjust human behavior as opposed to finance repair of infrastructure and provide economic relief. Rebuilding a road or funding a shelter is much easier for a government than convincing a population to change basic behavior to limit the spread of disease. This aspect of infectious disease outbreaks and government challenges supports the Chinese government efforts and timing of action for the current COVID-19 outbreak as opposed to the frequent criticisms being delivered by media "experts."

The global economic impact of the COVID-19 outbreak has been obvious. China trade has been restricted throughout the world with heavy impact for China and those nations that economically interact with China. Chinese manufacturing has suffered with limits to labor force interaction at work to contain the contagion and decreased world demand for goods due to fear of spread of the disease. Human travel for business and pleasure to and from China has decreased to the point of relative nonexistence. Supporting the assertion for the global economic impact of COVID-19, note that world stock exchanges have fluctuated wildly as news of the outbreak is released. The anticipated threat to a national economy adds to the stress for a national government when confronted with a potential new disease outbreak, leading to hesitation in publicly reacting to initial reports and informing the outside world.

Both immediate and long-term social challenges are a major difficulty in controlling the current COVID-19 outbreak and potential future outbreaks. First, limiting the movement of those with known infection exposure to avoid disease spread requires the participation of the restricted individuals. While many will understand the need for restricted interaction with the community, many others will consider the restriction a violation of their human rights. Effective public health messaging to a community is essential for success in obtaining social support for disease containment strategies. Yet, effective public health messaging, particularly to convince a population to limit their activities, must be culturally and socially competent as well as compelling without overstating known evidence. In essence, public health messaging regarding a disease outbreak such as COVID-19 is difficult, particularly in multicultural populations. Further, public health agencies are most often staffed for daily operations and do not have the staffing capacity for close monitoring of exposures. This staffing problem for public health agencies leads to a requirement that those in a community voluntarily act to contain infection outbreaks.

The COVID-19 outbreak has the potential to become a global pandemic. Containment of the outbreak requires the best of public health actions and skills. Missteps will occur because of the human nature of both those infected and the health responders themselves. Important for all who are providing health and medical services during this event is to recognize the broad impact of such a disease outbreak. It is necessary to understand the concerns of those who must support the efforts to contain the outbreak, including the political, economic, and social impacts of each action taken in the overall effort to support global security in relation to COVID-19.

(C) World Association for Disaster and Emergency Medicine, 2020. This is an Open Access article, distributed under the terms of the Creative Commons Attribution licence (http://creativecommons.org/licenses/by/4.0/), which permits unrestricted re-use, distribution, and reproduction in any medium, provided the original work is properly cited. 